\title{
Acetylcholinesterase and Butyrylcholinesterase Inhibitory Activities of $\beta$-Carboline and Quinoline Alkaloids Derivatives from the Plants of Genus Peganum
}

\author{
Ting Zhao, ${ }^{1}$ Ke-min Ding, ${ }^{1}$ Lei Zhang, ${ }^{1}$ Xue-mei Cheng, ${ }^{1,2,3}$ \\ Chang-hong Wang, ${ }^{1,2,3}$ and Zheng-tao Wang ${ }^{1,2,3}$ \\ ${ }^{1}$ Institute of Chinese Materia Medica, Shanghai University of Traditional Chinese Medicine, \\ 1200 Cailun Road, Zhangjiang Hi-Tech Park, Shanghai 201210, China \\ ${ }^{2}$ The MOE Key Laboratory for Standardization of Chinese Medicines and The SATCM Key Laboratory for \\ New Resources and Quality Evaluation of Chinese Medicines, Shanghai 201210, China \\ ${ }^{3}$ Shanghai R\&D Center for Standardization of Chinese Medicines, Shanghai 201210, China \\ Correspondence should be addressed to \\ Chang-hong Wang; wchcxm@hotmail.com and Zheng-tao Wang; wangzht@hotmail.com
}

Received 29 June 2012; Accepted 29 January 2013

Academic Editor: A. Hamid A. Hadi

Copyright (C) 2013 Ting Zhao et al. This is an open access article distributed under the Creative Commons Attribution License, which permits unrestricted use, distribution, and reproduction in any medium, provided the original work is properly cited.

It was reported that the main chemical constituents in plants of genus Peganum were a serial of $\beta$-carboline and quinoline alkaloids. These alkaloids were quantitatively assessed for selective inhibitory activities on acetylcholinesterase (AChE) and butyrylcholinesterase (BChE) by in vitro Ellman method. The results indicated that harmane was the most potent selective AChE inhibitor with an $\mathrm{IC}_{50}$ of $7.11 \pm 2.00 \mu \mathrm{M}$ and $\mathrm{AChE}$ selectivity index (SI, $\mathrm{IC}_{50}$ of $\mathrm{BChE} / \mathrm{IC}_{50}$ of $\mathrm{AChE}$ ) of 10.82 . Vasicine was the most potent $\mathrm{BChE}$ inhibitor with feature of dual $\mathrm{AChE} / \mathrm{BChE}$ inhibitory activity, with an $\mathrm{IC}_{50}$ versus $\mathrm{AChE} / \mathrm{BChE}$ of $13.68 \pm$ $1.25 / 2.60 \pm 1.47 \mu \mathrm{M}$ and AChE SI of 0.19. By analyzing and comparing the $\mathrm{IC}_{50}$ and SI of those chemicals, it was indicated that the $\beta$-carboline alkaloids displayed more potent AChE inhibition but less BChE inhibition than quinoline alkaloids. The substituent at the $\mathrm{C} 7$ position of the $\beta$-carboline alkaloids and $\mathrm{C} 3$ and $\mathrm{C} 9$ positions of quinoline alkaloids played a critical role in $\mathrm{AChE}$ or $\mathrm{BChE}$ inhibition. The potent inhibition suggested that those alkaloids may be used as candidates for treatment of Alzheimer's disease. The analysis of the quantitative structure-activity relationship of those compounds investigated might provide guidance for the design and synthesis of $\mathrm{AChE}$ and $\mathrm{BChE}$ inhibitors.

\section{Introduction}

Alzheimer's disease (AD) was characterized by dementia that typically begins with subtle recognition failure and poor memory. It slowly becomes more severe and, eventually, incapacitating. The cholinergic system seemed particularly susceptible to synapse loss, especially in cortical regions associated with memory and executive function [1]. Recent studies showed that the main cause of the loss of cognitive functions in $\mathrm{AD}$ patients was a continuous decline of the cholinergic neurotransmission in cortical and other regions of the human brain [2]. Acetylcholinesterase (AChE) and butyrylcholinesterase (BChE) are hydrolytic enzymes that act on acetylcholine $(\mathrm{ACh})$ to terminate its actions in the synaptic cleft by cleaving the neurotransmitter to choline and acetate. Both enzymes are present in the brain and detected in neurofibrillary tangles and neuritic plaques. It was suggested that AChE predominates in the healthy brain, with $\mathrm{BChE}$ considered to play a minor role in regulating brain ACh levels. However, BChE activity progressively increases in patients with $\mathrm{AD}$, while $\mathrm{AChE}$ activity remains unchanged or declines. Both enzymes therefore represent legitimate therapeutic targets for ameliorating the cholinergic deficit considered to be responsible for the declines in cognitive, behavioral, and global functioning characteristics of $\mathrm{AD}$ [3]. Despite the unknown etiology of $\mathrm{AD}$, those findings supported that it was needed to control the activity of the cholinesterase (ChE) at different stages of $\mathrm{AD}$ progression. One of the most effective 
treatment strategies was suggested to restrain cholinergic function and elevate ACh level through inhibiting AChE and BChE. Therefore, AChE and BChE inhibitors were developed for the treatment of $\mathrm{AD}[4,5]$.

The history of drug discovery showed that plants were rich sources of new active compounds, and many synthetic drugs owed their origin to plant-based medicine. The genus Peganum consists of six species and one subspecies and three of them, that is, $P$. harmala Linn, $P$. nigellastrum Bunge, and $P$. multisectum (Maxim.) Bobr, are mainly distributed in the arid and semiarid areas in the northwest of China [6]. P. harmala is a well-known and effective herbal medicine in Turkey, Iran, and China [6-8]. The seeds and whole plants appear to possess medicinal properties and can be used to treat various ailments including rheumatism, hypertension, diabetes, and asthma jaundice and as antiparasitic agents [6, 9-11]. It was reported that the main chemical constituents in the seeds and whole plant of genus Peganum were a serial of $\beta$-carboline and quinoline alkaloids [12, 13].

As part of the same project, we first reported the screening of AChE inhibition activity of seeds extracts from genus Peganum with rapid bioautographic assay on TLC plates $[14,15]$. It was found that the alkaloids fraction (mainly $\beta$-carboline and quinoline alkaloids) showed potential inhibitory effects on the AChE activity. A number of alkaloids including two new compounds nigellastrine I and nigellastrine II, along with eight known alkaloids, vasicinone, vasicine, harmine, deoxyvasicinone, deoxyvasicine, harmaline, harmol, and harmane, were isolated with their structures identified from $P$. nigellastrum Bunge, and their AChE inhibition activity was semiquantitatively evaluated by TLC-bioautographic assay [14]. Subsequently, intrigued by the interesting biological activities, Boerth and Rasapalli developed a synthetic route for nigellastrine, vasicinone, and luotonins [16]. In addition, it was also proved that the $\beta$ carboline alkaloids from $P$. harmala exhibited improvement effects on learning and memory of model dementia mice induced by aluminum [17].

The present study was undertaken to quantificationally evaluate the inhibitory activity of those alkaloids against $\mathrm{AChE}$ and BChE by in vitro Ellman method [18, 19]. Furthermore, by comparing the $\mathrm{IC}_{50}$ values and $\mathrm{AChE}$ selectivity index (SI, $\mathrm{IC}_{50}$ of $\mathrm{BChE} / \mathrm{IC}_{50}$ of $\mathrm{AChE}$ ) and analyzing the structure-activity relationship of those compounds investigated on selective $\mathrm{AChE}$ or $\mathrm{BChE}$ inhibition, it could provide a direction for the design and synthesis of new AChE and BChE inhibitors.

\section{Materials and Methods}

2.1. Chemicals and Instruments. The following chemicals were obtained from Sigma-Aldrich (USA): AChE from Electrophorus electricus, BChE from equine serum, acetylthiocholine iodide, butyrylthiocholine iodide, 5,5' -dithiobisbis-nitrobenzoic acid (DTNB), L-glutathione (L-GSH), harmaline, harmine, harmane, 1,2,3,4-tetrahydroharmane-3carboxylic acid, and galanthamine; harmalol hydrochloride dehydrate and harmol were purchased from Wako
Pure Chemical Industries, Ltd. (Japan); vasicine, vasicinone, deoxyvasicinone, and deoxyvasicine were separated and purified in our laboratory from seeds of $P$. harmala, and nigellastrine I and nigellastrine II were separated and purified in our laboratory from seeds of $P$. nigellastrum ( $\geq 98 \%$ purity), and their physical and spectral data were in good agreement with the literature data [14]. The structures of those compounds investigated were showed in Figure 1.

Microplate reader (Power wave XS, Bio-Tek Instruments, Winooski, VT, USA), precise $\mathrm{pH}$ instrument (PB-10, sartorius, Germany), and Eyela bath SB-9 (NTT-2200, Tokyo Rikakikal Co. Ltd.) were used.

2.2. Preparation of Solutions. The enzymes AChE and BChE were dissolved in $20 \mathrm{mM}$ sodium phosphate buffer ( $\mathrm{pH} 7.6$ ) to make the $3.47 \mathrm{unit} / \mathrm{mL}$ stock solution, and the solutions were stored at $-80^{\circ} \mathrm{C}$ before use. The stock solutions of the test compounds (harmaline, harmine, harmalol, harmol, harmane, vasicine, 1,2,3,4-tetrahydroharmane-3-carboxylic acid, vasicinone, deoxyvasicinone, deoxyvasicine, nigellastrine I, nigellastrine II, and galanthamine) were prepared, respectively, by dissolving an adequate quantity of each compound in $0.2 \%$ DMSO to obtain $20 \mathrm{mM}$ solutions. All the stock solutions were diluted to a series of concentrations with $20 \mathrm{mM}$ sodium phosphate buffer solution ( $\mathrm{pH} 7.6$ ) before each experiment. DTNB-phosphate-ethanol reagent was prepared as follows: to $12.4 \mathrm{mg}$ of DTNB dissolved in $120 \mathrm{~mL}$ of $96 \%$ ethanol, $80 \mathrm{~mL}$ of distilled water and $50 \mathrm{~mL}$ of $0.1 \mathrm{mM}$ phosphate buffer ( $\mathrm{pH} 7.6)$ were added [20].

2.3. In Vitro Anticholinesterase Assays. The AChE and BChE activity assay was carried out using acetylthiocholine iodide and butyrylthiocholine iodide as substrates, respectively, based on a colorimetric method, as described previously [18-20]. $10 \mu \mathrm{L}$ of the test compounds solution in $0.2 \%$ DMSO, $79 \mu \mathrm{L}$ of $20 \mathrm{mM}$ sodium phosphate buffer $(\mathrm{pH} 7.6)$, and $1 \mu \mathrm{L}$ enzyme preparation (with final concentrations: $0.087 \mathrm{unit} / \mathrm{mL}$ for $\mathrm{AChE}$, or $0.035 \mathrm{unit} / \mathrm{mL}$ for $\mathrm{BChE}$, and final concentrations: 1 to $500 / 1000 \mu \mathrm{M}$ for compounds tested) were mixed and preincubated for $15 \mathrm{~min}$. To the mixture, $10 \mu \mathrm{L}$ substrate solution was added (final concentrations $1.5 \mathrm{mM}$ for acetylthiocholine iodide, or $4 \mathrm{mM}$ for butyrylthiocholine iodide) and incubated for $30 \mathrm{~min}$. The reaction was stopped by adding $900 \mu \mathrm{L}$ DTNB-phosphate-ethanol reagent. The absorption was read immediately at $412 \mathrm{~nm}$ on a microplate reader. The concentration of the test compound required to inhibit $\mathrm{AChE}$ or BChE activity by $50 \%\left(\mathrm{IC}_{50}\right)$ was calculated using an enzyme inhibition dose response curve, with galanthamine as a positive control and L-GSH as standard to draw the standard curves. AChE SI was calculated by using the following formula: $\mathrm{SI}=\mathrm{IC}_{50}$ of $\mathrm{BChE} / \mathrm{IC}_{50}$ of AChE.

2.4. Data Analysis. The assays were conducted in triplicate, and all tabulated results were expressed as means $\pm \mathrm{SD}$, and the $\mathrm{IC}_{50}$ values were calculated by Boltzmann's dose response analysis using Origin 8.0 software. 
<smiles>COc1ccc2c3c([nH]c2c1)C(C)=NCC3</smiles>

Harmine<smiles>Cc1nccc2c1[nH]c1cc(O)ccc12</smiles>

Harmol<smiles>c1ccc2c(c1)CN1CCCC1=N2</smiles>

Deoxyvasicine
Harmaline<smiles>Cc1nccc2c1[nH]c1ccccc12</smiles>

Harmane<smiles>O=c1c2ccccc2nc2n1CCC2O</smiles>

Vasicinone
Harmalol<smiles>OC1CCN2Cc3ccccc3N=C12</smiles>

Vasicine<smiles>O=c1c2ccccc2nc2n1CCC2</smiles>

Deoxyvasicinone<smiles>Cc1ncc(C2CCc3nc4ccccc4c(=O)n32)c2c1[nH]c1ccccc12</smiles>

Nigellastrine I<smiles>CC1NC(C(=O)O)=Cc2c1[nH]c1ccccc21</smiles>

1, 2, 3, 4-tetrahydroharmane-3-carboxylic acid<smiles>CC1=NCC(C2CCc3nc4ccccc4c(=O)n32)c2c1[nH]c1ccccc21</smiles>

Nigellastrine II

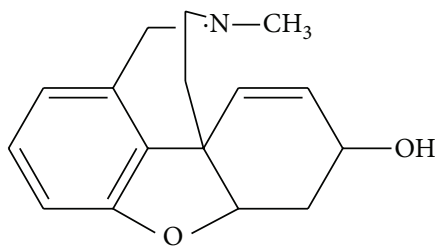

Galanthamine

FIGURE 1: Structures of the compounds investigated.

\section{Results}

The inhibitory activities of the $\beta$-carboline and quinoline alkaloids on $\mathrm{AChE}$ and $\mathrm{BChE}$ were evaluated in vitro using an inhibition assay with AChE (electric eel) and BChE (equine serum) and were summarized in Table 1.

First of all, it was observed that the inhibition data of reference compounds galanthamine within the limits of the different enzyme source and assay experimental conditions are in good agreement with the literature data [21].

All tested compounds exhibited some degree of activity on both $\mathrm{AChE}$ and $\mathrm{BChE}$, and their $\mathrm{IC}_{50}$ values were in the low micromolar range for at least one enzyme, with the exception of compounds deoxyvasicine and 1,2,3,4tetrahydroharmane-3-carboxylic acid. Harmane showed the most potent inhibitory activity with $\mathrm{IC}_{50}$ value of $7.11 \pm$ $2.00 \mu \mathrm{M}$ against AChE. However, harmane had a low inhibitory activity against $\mathrm{BChE}\left(\mathrm{IC}_{50}\right.$ of $\left.76.91 \pm 1.57 \mu \mathrm{M}\right)$. Harmine and harmaline significantly inhibited AChE activity with $\mathrm{IC}_{50}$ values of $9.05 \pm 1.08 \mu \mathrm{M}$ and $10.58 \pm 2.01 \mu \mathrm{M}$, but had lower inhibitory activity against BChE with $\mathrm{IC}_{50}$ values of $75.07 \pm 1.29 \mu \mathrm{M}$ and $101.39 \pm 1.39 \mu \mathrm{M}$, respectively. Vasicine exhibited strong inhibition both on AChE and BChE activities with $\mathrm{IC}_{50}$ values of $13.68 \pm 1.25$ and $2.60 \pm$ $1.47 \mu \mathrm{M}$, respectively. As the main metabolites of harmaline and harmine in vivo [22, 23], harmalol and harmol exhibited 
TABLE 1: Inhibitory activity $\left(\mathrm{IC}_{50}\right)$ and selectivity index (SI) of the compounds investigated against AChE and BChE.

\begin{tabular}{lccc}
\hline \multirow{2}{*}{ Compounds } & \multicolumn{2}{c}{$\mathrm{IC}_{50}(\mu \mathrm{M} \pm \mathrm{SD})$} & $\mathrm{SI}$ \\
& $\mathrm{AChE}$ & $\mathrm{BChE}$ & \\
Galanthamine & $1.18 \pm 1.05$ & $/$ & \\
& $0.8[21]$ & $7.3[21]$ & 9.13 \\
Harmane & $7.11 \pm 2.00$ & $76.91 \pm 1.57$ & 10.82 \\
Harmine & $9.05 \pm 1.08$ & $75.07 \pm 1.29$ & 8.30 \\
Harmaline & $10.58 \pm 2.01$ & $101.39 \pm 1.39$ & 9.58 \\
Harmol & $21.58 \pm 1.39$ & $8.21 \pm 3.65$ & 0.38 \\
Harmalol & $27.88 \pm 1.13$ & $9.48 \pm 2.03$ & 0.34 \\
Vasicine & $13.68 \pm 1.25$ & $2.60 \pm 1.47$ & 0.19 \\
Nigellastrine II & $40.46 \pm 1.09$ & $9.26 \pm 1.47$ & 0.23 \\
Nigellastrine I & $70.50 \pm 1.14$ & $18.24 \pm 3.23$ & 0.26 \\
Vasicinone & $370.78 \pm 1.07$ & - & \\
Deoxyvasicinone & $294.44 \pm 1.47$ & - & \\
Deoxyvasicine & - & - & \\
1,2,3,4- & & & \\
tetrahydroharmane-3- & & & \\
carboxylic & - & & \\
acid & & & \\
\hline
\end{tabular}

$\mathrm{IC}_{50}$ values were determined by regression analyses and expressed as the means $\pm \mathrm{SD}$ of three replicate determinations. SI is the $\mathrm{AChE}$ selectivity index defined as $\mathrm{IC}_{50} \mathrm{BChE} / \mathrm{IC}_{50} \mathrm{AChE}$ affinity ratio.

-: no inhibitory activity.

moderate inhibitory activity against $\mathrm{AChE}$ with $\mathrm{IC}_{50}$ values of $27.88 \pm 1.13$ and $21.58 \pm 1.39 \mu \mathrm{M}$ and stronger inhibitory activity against $\mathrm{BChE}$ with $\mathrm{IC}_{50}$ values of $9.48 \pm 2.03$ and $8.21 \pm 3.65 \mu \mathrm{M}$. Nigellastrine I and nigellastrine II had stronger inhibitory activity against $\mathrm{BChE}$ with $\mathrm{IC}_{50}$ values of $18.24 \pm 3.23$ and $9.26 \pm 1.47 \mu \mathrm{M}$, but with weaker inhibitory activity against $\mathrm{AChE}$ with $\mathrm{IC}_{50}$ values of $70.50 \pm 1.14$ and $40.46 \pm 1.09 \mu \mathrm{M}$.

\section{Discussion}

Results from previous studies showed that the alkaloids fraction containing mainly $\beta$-carboline and quinoline alkaloids from the seeds of $P$. nigellastrum exhibited potential inhibitive activity on AchE [14]. In our ongoing studies, the inhibitory activities of those individual $\beta$-carboline and quinoline alkaloids separated from genus Peganum on AChE and BChE were determined using the in vitro Ellman method. Based on the inhibitory potency and selectivity of those alkaloids on $\mathrm{AChE}$ and BChE, the structure-activity relationship of those alkaloids could be speculated as follows.

Amongst the series of $\beta$-carboline alkaloids (Figure 1 ), varying the substituent at $\mathrm{C} 7$ modulated the ChE inhibitory profile. The presence of an O-methyl substituent at C7 (harmine) led to the inhibition and selection on AChE slightly reduce with $\mathrm{IC}_{50}$ of $9.05 \pm 1.08 \mu \mathrm{M}$ and $\mathrm{AChE} \mathrm{SI}$ of 8.30 , compared to harmane with $\mathrm{IC}_{50}$ of $7.11 \pm 2.00 \mu \mathrm{M}$ and AChE SI of 9.13. No obvious difference was observed between the inhibitory activity of harmane and harmine against BChE. When oxidation at C7 occurs, such as harmol, the inhibition against $\mathrm{BChE}$ was enhanced $\left(\mathrm{IC}_{50}=8.21 \pm\right.$ $3.65 \mu \mathrm{M})$ but with reduced activity on $\mathrm{AChE}\left(\mathrm{IC}_{50}=21.58 \pm\right.$ $1.39 \mu \mathrm{M})$. Therefore the hydroxyl substituent at C7 obviously reduced the selectivity for AChE inhibition. According to the above analysis, C7 could be regarded as a possible active site for $\beta$-carboline alkaloids, and varying the substituent at C7 could significantly affect the inhibition on AChE and $\mathrm{BChE}$. The double bond at $\mathrm{C} 3-\mathrm{C} 4$ seemed to have a certain degree of influence on the inhibitory activity against BChE, as demonstrated by the $\mathrm{IC}_{50}$ values of harmaline and harmine. As the main $\mathrm{O}$-demethylation metabolites of harmaline and harmine, harmalol and harmol showed moderate inhibitory potency on $\mathrm{AChE}$ with $\mathrm{IC}_{50}$ values of $27.88 \pm 1.13$ and $21.58 \pm 1.39 \mu \mathrm{M}$ and stronger inhibitory potency on $\mathrm{BChE}$ with $\mathrm{IC}_{50}$ values of $9.48 \pm 2.03$ and $8.21 \pm 3.65 \mu \mathrm{M}$. Namely, the selective inhibition of harmalol and harmol versus AChE deduced compared with their parent compound harmaline and harmine. On the contrary, their selective inhibition against BChE enhanced.

Amongst the quinoline alkaloids (Figure 1), vasicine was identified as the potent inhibitor with $\mathrm{IC}_{50}$ values of $13.68 \pm$ $1.25 \mu \mathrm{M}$ on $\mathrm{AChE}$ and $2.60 \pm 1.47 \mu \mathrm{M}$ on BChE, respectively. Selective BChE inhibitors have already been reported to increase the ACh levels in the brain and to also reduce the formation of abnormal amyloid. Therefore, the discovery of potent and highly selective BChE inhibitors and/or of dual $\mathrm{AChE} / \mathrm{BChE}$ inhibitors is an actively pursued goal in $\mathrm{AD}$ treatment drug discovery [21]. Very interestingly, although with poor selectivity, vasicine may be a very potential lead compound with the feature of dual AChE/BChE inhibitory activity.

Vasicinone and deoxyvasicinone possessing a carbonylation at C9 or dehydroxylation at C3 exhibited no much inhibitory activity on either $\mathrm{AChE}$ or $\mathrm{BChE}$ with $\mathrm{IC}_{50}$ values of $370.78 \pm 1.07$ and $294.44 \pm 1.47 \mu \mathrm{M}$ on $\mathrm{AChE}$ and with $\mathrm{IC}_{50}$ values of above $1000 \mu \mathrm{M}$ on BChE. Those data indicated that the inhibitive potency of quinoline alkaloids on both $\mathrm{AChE}$ and BChE was affected by the substitution at C3 and C9. Deoxyvasicine, possessing a carbonylation reaction at $\mathrm{C} 9$ and dehydroxylation at C3 simultaneously, showed no inhibitory potency on both $\mathrm{AChE}$ and $\mathrm{BChE}$ with larger $\mathrm{IC}_{50}$ values more than $1000 \mu \mathrm{M}$.

As seen from Table 1, nigellastrine I and nigellastrine II (Figure 1), two dimers of quinoline (deoxyvasicinone) and $\beta$ carboline alkaloids (harmane or dehydroharmane), displayed a stronger activity on BChE inhibition and weaker activity on AChE inhibition. When compared with deoxyvasicinone, those dimers enhanced the inhibitor potency on both AChE and BChE, but more on BChE. On the other hand, by comparison with harmane, the two dimmers seemed to have certain inhibitory selectivity for BChE.

From the above analysis, harmane, harmine, and harmaline, the main active constituent in genus Peganum, had good selective inhibitory activities against $\mathrm{AChE}$, and the oxidation of the substituent at C7 could significantly modify the inhibitory potency and selectivity for both AChE and BChE. C3 and C9 positions of quinoline alkaloids were inferred to be the active site for both $\mathrm{AChE}$ and $\mathrm{BChE}$ 
inhibition. Moreover, it was found that, by the polymerization of quinoline and carboline alkaloids, the inhibitory activity declined on AChE, but increased on BChE. In the light of those findings, it could be concluded that the alkaloids from the plants of genus Peganum showed inhibitory activity against both $\mathrm{AChE}$ and $\mathrm{BChE}$. In addition, those findings may provide some guidance for the design and synthesis or semisynthesis of potential inhibitors on AChE or BChE.

\section{Conflict of Interests}

The authors have declared that there is no conflict of interests.

\section{Acknowledgments}

The authors gratefully acknowledge the award from the Key Program of Joint Funds of the National Natural Science Foundation of China and Xinjiang Uygur Autonomous Region of China (no. U1130303), the National Nature Science Foundation of China (no. 81173119), the Key Project of Ministry of Science and Technology of China (2012ZX09103201051), and the Program for Shanghai Innovative Research Team in University (2009) to Professor C.-H. Wang for the financial support of this study. The authors would also like to thank Professor Shouming Zhong for providing language help during the writing of this paper.

\section{References}

[1] J. A. Bailey and D. K. Lahiri, "A novel effect of rivastigmine on pre-synaptic proteins and neuronal viability in a neurodegeneration model of fetal rat primary cortical cultures and its implication in Alzheimer's disease," Journal of Neurochemistry, vol. 112, no. 4, pp. 843-853, 2010.

[2] D. Schuster, M. Spetea, M. Music et al., "Morphinans and isoquinolines: acetylcholinesterase inhibition, pharmacophore modeling, and interaction with opioid receptors," Bioorganic \& Medicinal Chemistry, vol. 18, no. 14, pp. 5071-5080, 2010.

[3] N. H. Greig, D. K. Lahiri, and K. Sambamurti, "Butyrylcholinesterase: an important new target in Alzheimer's disease therapy," International Psychogeriatrics, vol. 14, supplement 1 , pp. 77-91, 2002.

[4] I. Orhan, B. Şener, M. I. Choudhary, and A. Khalid, "Acetylcholinesterase and butyrylcholinesterase inhibitory activity of some Turkish medicinal plants," Journal of Ethnopharmacology, vol. 91, no. 1, pp. 57-60, 2004.

[5] T. Mohamed and P. P. N. Rao, "Design, synthesis and evaluation of 2,4-disubstituted pyrimidines as cholinesterase inhibitors," Bioorganic and Medicinal Chemistry Letters, vol. 20, no. 12, pp. 3606-3609, 2010.

[6] X. M. Cheng, T. Zhao, T. Yang, C. H. Wang, S. W. A. Bligh, and Z. T. Wang, "HPLC fingerprints combined with principal component analysis, hierarchical cluster analysis and linear discriminant analysis for the classification and differentiation of Peganum sp. indigenous to China," Phytochemical Analysis, vol. 21, no. 3, pp. 279-289, 2010.

[7] M. Kartal, M. L. Altun, and S. Kurucu, "HPLC method for the analysis of harmol, harmalol, harmine and harmaline in the seeds of Peganum harmala L," Journal of Pharmaceutical and Biomedical Analysis, vol. 31, no. 2, pp. 263-269, 2003.
[8] B. Hemmateenejad, A. Abbaspour, H. Maghami, R. Miri, and M. R. Panjehshahin, "Partial least squares-based multivariate spectral calibration method for simultaneous determination of beta-carboline derivatives in Peganum harmala seed extracts," Analytica Chimica Acta, vol. 575, no. 2, pp. 290-299, 2006.

[9] Chinese Pharmacopoeia Committee, Drug Standards of the Ministry of Public Health of the People's Republic of China, Uygur Pharmaceutical Section, 1998.

[10] J. Riba, M. Valle, G. Urbano, M. Yritia, A. Morte, and M. J. Barbanoj, "Human pharmacology of ayahuasca: subjective and cardiovascular effects, monoamine metabolite excretion, and pharmacokinetics," Journal of Pharmacology and Experimental Therapeutics, vol. 306, no. 1, pp. 73-83, 2003.

[11] A. Tahraoui, J. El-Hilaly, Z. H. Israili, and B. Lyoussi, "Ethnopharmacological survey of plants used in the traditional treatment of hypertension and diabetes in south-eastern Morocco (Errachidia province)," Journal of Ethnopharmacology, vol. 110, no. 1, pp. 105-117, 2007.

[12] Z. L. Fan and X. S. Yao, "The research of constituents and pharmacology of the genus Peganum," Journal of Shenyang College of Pharmacy, vol. 9, pp. 144-151, 1992.

[13] T. Zhao, C. H. Wang, and Z. T. Wang, "Chemical constituents and pharmacologic actions of genus Peganum: research advances," Journal of International Pharmaceutical Research, vol. 37, no. 5, pp. 333-345, 2010.

[14] X. Y. Zheng, Z. J. Zhang, G. X. Chou et al., "Acetylcholinesterase inhibitive activity-guided isolation of two new alkaloids from seeds of Peganum nigellastrum Bunge by an in vitro TLCbioautographic assay," Archives of Pharmacal Research, vol. 32, no. 9, pp. 1245-1251, 2009.

[15] X. Y. Zheng, L. Zhang, X. M. Cheng, Z. J. Zhang, C. H. Wang, and Z. T. Wang, "Identification of acetylcholinesterase inhibitors from seeds of plants of genus Peganum by thinlayer chromatography-bioautography," JPC-Journal of Planar Chromatography-Modern TLC, vol. 24, no. 6, pp. 470-474, 2011.

[16] J. A. Boerth and S. Rasapalli, "Studies toward the total synthesis of quinazoline alkaloids: vasicinone, luotonin, and nigellastrine," in Proceedings of the 244th ACS National Meeting of Exposition, Philadelphia, Pa, USA, August 2012, CHED-304, http://abstracts.acs.org/chem/244nm/program/view.php.

[17] J. R. Fu, L. Teng, X. Y. Dai, and F. S. Yu, "Optimization of extraction and purification of harmala alkaloids and the effects on learning and memory of model dementia mice induced by aluminum," Chinese Traditional Patent Medicine, vol. 33, pp. 975-979, 2011.

[18] G. L. Ellman, K. D. Courtney, V. Andres, and R. M. Featherstone, "A new and rapid colorimetric determination of acetylcholinesterase activity, Biochemical Pharmacology, vol. 7, no. 2, pp. 88-95, 1961.

[19] M. A. Gordon, D. E. Carpenter, H. W. Barrett, and I. B. Wilson, "Determination of the normality of cholinesterase solutions," Analytical Biochemistry, vol. 85, no. 2, pp. 519-527, 1978.

[20] V. Gorun, I. Proinov, V. Baltescu, G. Balaban, and O. Barzu, "Modified Ellman procedure for assay of cholinesterases in crude enzymatic preparations," Analytical Biochemistry, vol. 86, no. 1, pp. 324-326, 1978.

[21] B. Tasso, M. Catto, O. Nicolotti et al., "Quinolizidinyl derivatives of bi- and tricyclic systems as potent inhibitors of acetyl- and butyrylcholinesterase with potential in Alzheimer's disease," European Journal of Medicinal Chemistry, vol. 46, no. 6, pp. 2170-2184, 2011. 
[22] T. Zhao, S. S. Zheng, B. F. Zhang et al., "Metabolic pathways of the psychotropic-carboline alkaloids, harmaline and harmine, by liquid chromatography/mass spectrometry and NMR spectroscopy," Food Chemistry, vol. 134, no. 2, pp. 1096-1105, 2012.

[23] A. M. Yu, J. R. Idle, K. W. Krausz, A. Küpfer, and F. J. Gonzalez, "Contribution of individual cytochrome P450 isozymes to the $O$-demethylation of the psychotropic $\beta$-carboline alkaloids harmaline and harmine," Journal of Pharmacology and Experimental Therapeutics, vol. 305, no. 1, pp. 315-322, 2003. 

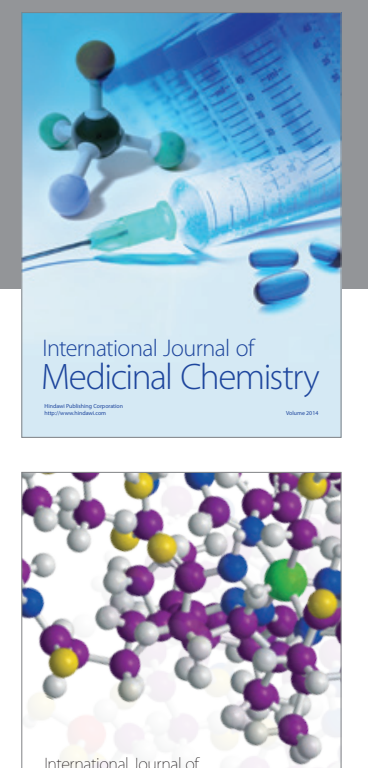

\section{Carbohydrate} Chemistry

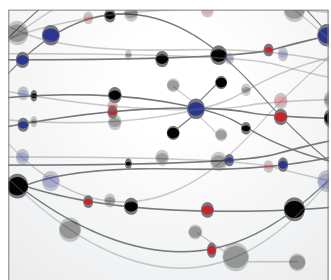

The Scientific World Journal
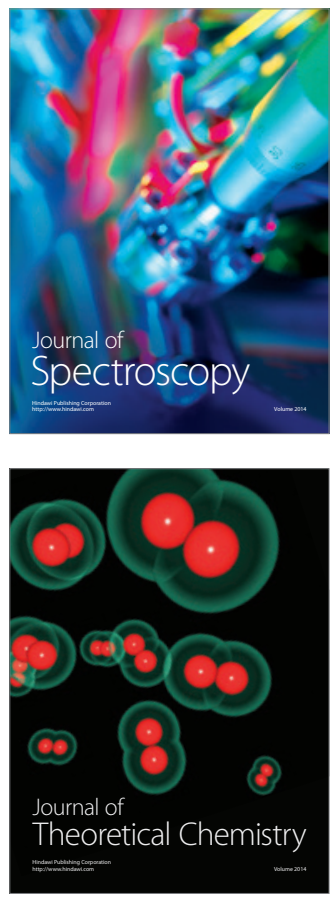
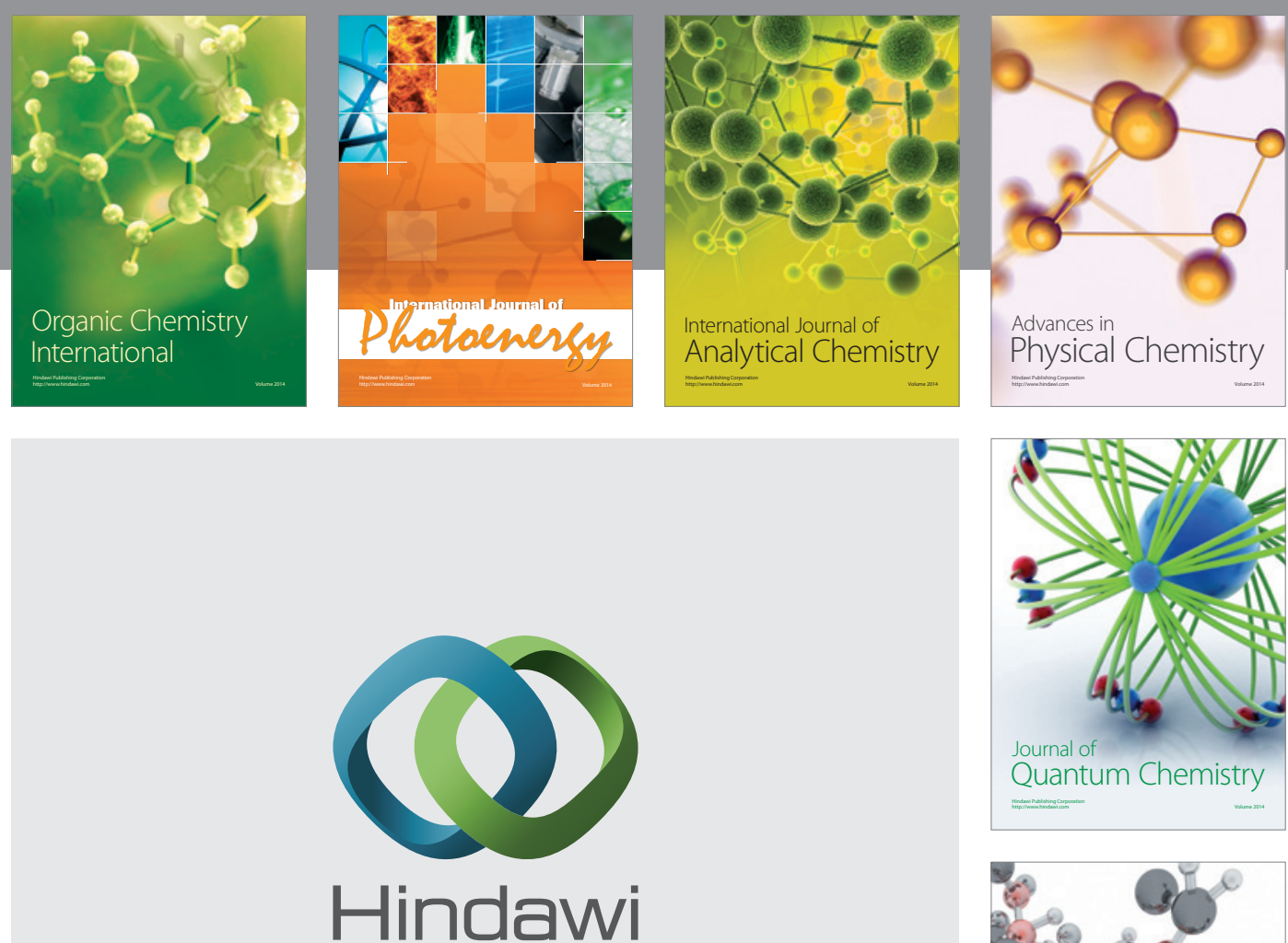

Submit your manuscripts at

http://www.hindawi.com

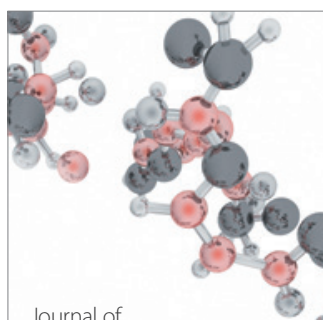

Analytical Methods

in Chemistry

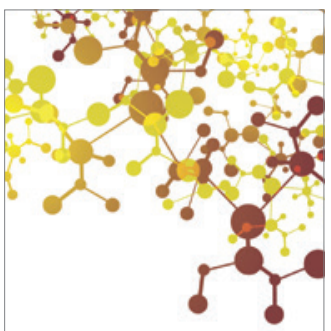

Journal of

Applied Chemistry

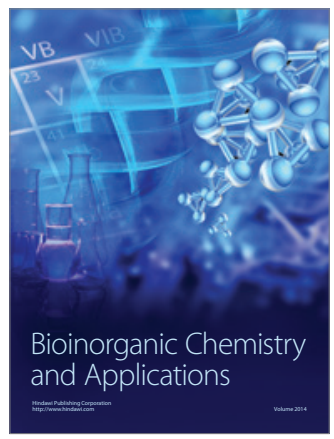

Inorganic Chemistry
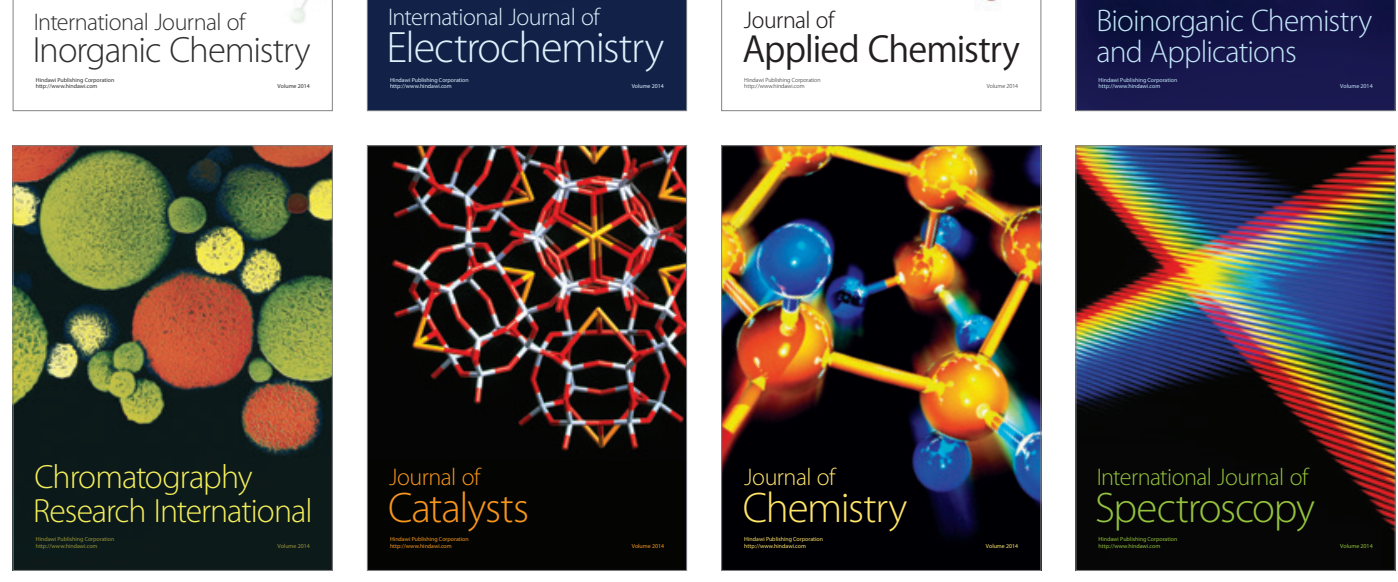